\title{
An innovative approach of compensatory learning mechanism (CLM) based on principles of self-directed learning amongst dental students
}

\author{
Saxsena, R., Patil, S., Ladkat, S., Kazi, M.M., Bhosale, A., Panchwadkar, D. \& Diwnay, S.
}

\begin{abstract}
Introduction: The missed learning experience of students due to absenteeism is a problem in medical education since it hampers a favourable teaching-learning outcome, resulting in less than optimum skills of the students. In order to overcome this problem, the authors have presented a novel mechanism of compensatory learning mechanism based on principles of adult learning.

Methods: The list of students absent for a particular session (theory/practical) was prepared, and allotted assignments were displayed on notice board after each session in standard format. After completion of one year, a feedback form was circulated to all participants wherein they were asked to record the experience about the compensatory learning mechanism (CLM) in a 15 item questionnaire with Likert type of responses from 1 to 5 . Assessment of the student's attendance \& performance was done for all participants.
\end{abstract}

Results: BDS III \& BDS IV students scored significantly higher in year 2014 as compared to 2013 ( $p<0.001$ for both groups) which was highly significant. BDS I \& BDS II students scored higher in year 2014 as compared to 2013 but results were not statistically significant $(p>0.05)$.

Conclusion: Students in professional institutions are self-directed adults who are motivated by internal drives. CLM provides an opportunity for these students to complete \& augment their learning.

Keywords: Medical education, Compensatory Learning Mechanism, Self-Directed learning, BDS

\section{Introduction}

Ideally in health care, the entire syllabus is important and mandatory to learn and the students cannot afford to miss out on any Teaching-Learning experience. The continuity of topics in the curriculum is important as the earlier topics form the foundation on which understanding of the later topics.

Corresponding author:

Nikhi JoshiDepartment of Prosthodontcs

Sinhgad Dental College \& Hospital,

STES CAMPUS,

Vadgaon,

Pune.

Email:nikijoshi@gmail.com
Universities in India by and large follow the rule of thumb that students who have less than 75 $\%$ attendance in theory and $80 \%$ attendance in practical classes will be ineligible to appear for university examinations. In this scenario, many students have developed a mind set to adjust for $75 \%$ to $80 \%$ attendance. Thus they miss out on those many learning hours. This eventually may lead to a less than optimum teachinglearning outcome, resulting in less than optimum skills of the outgoing students.

Unfortunately, the mind set of students is to just barely fulfil the minimum percentage of classes as mandated by the university. As a result, the topics, those students have missed, during the permissible period of the 20 to $25 \%$ absenteeism, are neglected. There is no system for students to ensure their learning of these missed topics. With the aim of bridging 
the lacunae of knowledge due to missed classes, the authors have introduced a novel and innovative mechanism called Compensatory Learning Mechanism (CLM).

CLM has been designed to compensate for the missed learning experience of the student who has been absent for a class/practical. A tailor made approach is designed for each student wherein he/she is made responsible for taking initiative to complete the learning process. The teacher's role here is more of a facilitator. In this mechanism, a compensatory theory/practical exercise is performed by the student for the missed lectures/ practical classes in the form of presentations, viva, tutorials, project, group discussions, seminars etc. under the guidance \& supervision of the faculty.

\section{Methodology}

Permission was taken from competent authorities for implementing the CLM \& ethical clearance was obtained from the institutional ethical committee. The study was conducted on all I, II, III \& IV year BDS students ( $n=287$ : BDS $I=91$, BDS $\|=61$, BDS $I I=65$, BDS IV=70) in respective departments of the Sinhgad Dental College \& Hospital, Pune. The details of implementation of CLM were explained to students \& faculty. The students \& respective teachers were informed verbally \& through circular for participation. The study was conducted from June 2013 up to March 2014. The following protocol was followed by the investigators:

1) The list of students absent for a particular session (theory/practical) was prepared and allotted assignments were displayed on notice board after each session in standard format.

2) The standard format entailing the name of student, session absent, compensatory mechanism allotted, whether CLM performed satisfactorily and acknowledgement of student and said teacher along with attestation of the head of department was obtained.

3) A monthly report was submitted to department head regarding the students who were consistently absent \& those who were not completing compensatory assignments.

4) List of such students was displayed on the notice board \& they were asked to meet concerned faculty for counselling. A written undertaking amounting to "Not to miss the future lectures and submit the compensatory assignment" was taken from these students.

\section{Details of the assignments}

Respective subject teachers had freedom to choose any form of T-L mechanism like tutorials/assignment//seminars/viva voce/practical or clinical exercise under supervision of the faculty.

\section{Assessment of outcomes:}

- After completion of one year, a feedback form was circulated to all participants wherein they were asked to record the experience about CLM in a 15 item questionnaire with Likert type of responses from 1 to 5 . The open ended questions were aimed to develop a range of responses that could give a qualitative assessment about the student experiences.

- The feedback-form consisted of 15 questions pertaining to the compensatory learning mechanism implemented in the academic year 2013 to 2014 .

- The validity of questionnaire feedback form was peer reviewed and validated by colleagues \& senior teachers as well as FAIMER faculty.

- Assessment of the student's attendance \& performance was done for all participants.

- The performance was assessed by calculating the improvement in scores obtained in I \& II internal assessments \& preliminary examination \& compared to the score with the performance of the student in the last year.

\section{Statistical analysis}

Data obtained from feedback forms along with the results of university final examinations of all the undergraduate years i.e. I to IV BDS was compiled on excel sheet (MS Office). The mean of the percentage marks obtained in the examination 2014 was compared with those obtained in the year 2013 for all the four undergraduate years by unpaired t test using statistical package for social sciences (SPSS v 
17.0, Chicago, III.) Percentage and frequency of the responses obtained from the feedback forms were also calculated.

\section{Results}

Comparison of mean marks percentages of 2014 and 2013 BDS III \& BDS IV students scored significantly higher in year 2014 as compared to 2013 ( $p<0.001$ for both groups) which was highly significant.

BDS I \& BDS II students scored higher in year 2014 as compared to 2013 but results were not statistically significant $(p>0.05)$.

\section{Results of responses obtained from the feedback:}

Questionnaire based feedback of I B.D.S students:

$31.9 \%$ strongly agreed and $58.2 \%$ agreed that students of health profession need $100 \%$ learning. $47.3 \%$ of students granted that CLM is a very good mechanism to motivate students for self-study and inculcate self-directed learning while $31.9 \%$ were neutral in this regard. $44 \%$ of students agreed that CLM helped them to get near $100 \%$ of their learning schedule. $42.9 \%$ agreed that their experience in CLM was good, and $39.6 \%$ agreed that CLM was effective to motivate students for learning and $38.5 \%$ agreed that CLM was implemented up to their satisfaction (Table 1).

Questionnaire based feedback of II B.D.S students:

$34.3 \%$ strongly agreed and $23.2 \%$ agreed that students of health profession need $100 \%$ learning. $31.3 \%$ of students granted that CLM is a very good mechanism to motivate students for self-study and inculcate self-directed learning. $29.3 \%$ of students agreed that CLM helped them to get near $100 \%$ of their learning schedule. $36.4 \%$ agreed that their experience in CLM was good, and $37.4 \%$ agreed that CLM was effective to motivate students for learning and $36.4 \%$ agreed that CLM was implemented up to their satisfaction (Table 2).

Questionnaire based feedback of III B.D.S students:

$30.1 \%$ strongly agreed and $29.1 \%$ agreed that students of health profession need $100 \%$ learning. $32 \%$ of students granted that CLM is a very good mechanism to motivate students for self-study and inculcate self-directed learning. $23.3 \%$ of students agreed that CLM helped them to get near $100 \%$ of their learning schedule. $20.4 \%$ agreed that their experience in CLM was good, and $24.3 \%$ had a neutral option for the same. $21.4 \%$ agreed that CLM was effective to motivate students for learning and $22.3 \%$ were neutral for the same. $25.2 \%$ agreed that CLM was implemented up to their satisfaction (Table 3).

Questionnaire based feedback of IV B.D.S students:

$30.8 \%$ strongly agreed and $18.3 \%$ of students were of the neutral opinion and $20.2 \%$ disagreed that students of health profession need $100 \%$ learning. $22.1 \%$ of students were neutral in their opinion regarding whether CLM is a very good mechanism to motivate students for self-study and inculcate self-directed learning. $30.8 \%$ were of a neutral opinion that their experience in CLM was good, and $26.9 \%$ agreed that CLM was effective to motivate students for learning and $20.2 \%$ were of the neutral opinion upon the question whether CLM was implemented up to their satisfaction (Table 4).

\section{Discussion}

Education is the process of receiving or giving systematic instruction, especially at a school or university. Education is an important tool for development of knowledge, skills and attitudes. Health education is related to providing information about all aspects of health. Health education includes environmental health, physical health, social health, emotional health, intellectual health, and spiritual health. Precisely health education can be defined as the standard by which individuals and groups of people learn to perform in a manner which helps in the promotion, maintenance, and restoration of health.

The health education curriculum consists of planned learning experiences which ultimately help students in attaining desirable attitude and practices related to critical health issues. It is essential to grasp maximum knowledge, skills and develop an attitude to become a competent health provider. Students or individuals who enrol in the health education cannot afford to miss out any lessons, clinics or practices taught in the institutions. 
Table 1: responses from the feedback I BDS $(n=91)$

\begin{tabular}{|c|c|c|c|c|c|c|c|c|c|c|}
\hline \multirow[b]{2}{*}{ Dental Health professionals need $100 \%$ learning } & \multicolumn{2}{|c|}{$\begin{array}{c}\text { Strongly } \\
\text { disagree(SD) }\end{array}$} & \multicolumn{2}{|c|}{$\begin{array}{l}\text { Disagree } \\
\text { (D) }\end{array}$} & \multicolumn{2}{|c|}{$\begin{array}{c}\text { Neutral } \\
(\mathrm{N})\end{array}$} & \multicolumn{2}{|c|}{$\begin{array}{l}\text { Agree } \\
\text { (A) }\end{array}$} & \multicolumn{2}{|c|}{$\begin{array}{c}\text { Strongly } \\
\text { agree (SA) }\end{array}$} \\
\hline & 4 & $(4.4 \%)$ & 2 & $(2.2 \%)$ & 3 & $(3.3 \%)$ & 53 & $(58.2 \%)$ & 29 & $(31.9 \%)$ \\
\hline $\begin{array}{l}\text { Compensatory Academic Mechanism (Self Directed } \\
\text { Learning) is very good mechanism for the same }\end{array}$ & 6 & $(6.6 \%)$ & 3 & $(3.3 \%)$ & 29 & $(31.3 \%)$ & 43 & $(47.3 \%)$ & 10 & $(11 \%)$ \\
\hline $\begin{array}{l}\text { The Compensatory Academic Mechanism (Self } \\
\text { Directed learning) helps you to get near -- } 100 \% \\
\text { learning of your schedule. }\end{array}$ & 2 & $(2.2 \%)$ & 11 & $(12.1 \%)$ & 29 & $(31.9 \%)$ & 40 & $(44 \%)$ & 9 & $(9.9 \%)$ \\
\hline $\begin{array}{l}\text { Your experience during Compensatory Academic } \\
\text { Mechanism (Self Directed learning) is good } \\
\text { The Compensatory Academic Mechanism (Self }\end{array}$ & 3 & $(3.3 \%)$ & 5 & $(5.5 \%)$ & 38 & $(41.8 \%)$ & 39 & $(42.9 \%)$ & 6 & $(6.6 \%)$ \\
\hline $\begin{array}{l}\text { Directed learning) is effective to motivate the students } \\
\text { for learning }\end{array}$ & 4 & $(4.4 \%)$ & 16 & $(17.6 \%)$ & 23 & $(25.3 \%)$ & 36 & (39.6\%) & 12 & $(13.2 \%)$ \\
\hline $\begin{array}{l}\text { The Compensatory Academic Mechanism (Self } \\
\text { Directed learning) was implemented -- to your } \\
\text { satisfaction. }\end{array}$ & 3 & $(3.3 \%)$ & 16 & $(17.6 \%)$ & 29 & $(31.9 \%)$ & 35 & (38.5\%) & 8 & $(8.8 \%)$ \\
\hline
\end{tabular}

Table 2: Responses from the feedback II BDS $(n=61)$

\begin{tabular}{|c|c|c|c|c|c|c|c|c|c|c|}
\hline & & SD & & $\mathrm{D}$ & & $\mathrm{N}$ & & A & & SA \\
\hline Dental Health professionals need $100 \%$ learning & - & - & - & - & - & - & - & - & - & - \\
\hline $\begin{array}{l}\text { Compensatory Academic Mechanism (Self Directed } \\
\text { Learning) is very good mechanism for the same }\end{array}$ & 1 & $(1 \%)$ & 1 & $(1 \%)$ & 15 & $(15.2 \%)$ & 31 & $(31.3 \%)$ & 13 & $(1.1 \%)$ \\
\hline $\begin{array}{l}\text { The Compensatory Academic Mechanism (Self } \\
\text { Directed learning) helps you to get near -- } 100 \% \\
\text { learning of your schedule. }\end{array}$ & 0 & $(0 \%)$ & 10 & $(10.1 \%)$ & 13 & $(13.1 \%)$ & 29 & $(29.3 \%)$ & 9 & (9.1\%) \\
\hline $\begin{array}{l}\text { Your experience during Compensatory Academic } \\
\text { Mechanism (Self Directed learning) is good } \\
\text { The Compensatory Academic Mechanism (Self }\end{array}$ & 2 & $(2 \%)$ & 3 & $(3 \%)$ & 12 & $(12.1 \%)$ & 36 & $(36.4 \%)$ & 8 & $(8.1 \%)$ \\
\hline $\begin{array}{l}\text { Directed learning) is effective to motivate the students } \\
\text { for learning }\end{array}$ & 1 & $(1 \%)$ & 6 & (6.1\%) & 15 & $(15.2 \%)$ & 37 & (37.4\%) & 2 & $(2 \%)$ \\
\hline $\begin{array}{l}\text { The Compensatory Academic Mechanism (Self } \\
\text { Directed learning) was implemented -- to your } \\
\text { satisfaction. }\end{array}$ & 0 & $(0 \%)$ & 3 & $(3 \%)$ & 17 & $(17.2 \%)$ & 36 & (36.4\%) & 5 & (5.1\%) \\
\hline
\end{tabular}

Table 3: Responses from the feedback III BDS $(n=70)$

\begin{tabular}{|c|c|c|c|c|c|c|c|c|c|c|}
\hline & & SD & & D & & $\mathrm{N}$ & & $A$ & & SA \\
\hline Dental Health professionals need $100 \%$ learning & 2 & $(1.9 \%)$ & 2 & $(1.9 \%)$ & 5 & $(4.9 \%)$ & 30 & $(29.1 \%)$ & 31 & $(30.1 \%)$ \\
\hline $\begin{array}{l}\text { Compensatory Academic Mechanism (Self Directed } \\
\text { Learning) is very good mechanism for the same }\end{array}$ & 4 & (3.9\%) & 15 & (14.6\%) & 14 & (13.6\%) & 33 & $(32 \%)$ & 4 & (3.9\%) \\
\hline $\begin{array}{l}\text { The Compensatory Academic Mechanism (Self } \\
\text { Directed learning) helps you to get near -- } 100 \% \\
\text { learning of your schedule. }\end{array}$ & 3 & $(2.9 \%)$ & 18 & (17.5\%) & 20 & (19.4\%) & 24 & (23.3\%) & 5 & (4.9\%) \\
\hline $\begin{array}{l}\text { Your experience during Compensatory Academic } \\
\text { Mechanism (Self Directed learning) is good } \\
\text { The Compensatory Academic Mechanism (Self }\end{array}$ & 2 & (1.9\%) & 18 & (17.5\%) & 25 & (24.3\%) & 21 & (20.4\%) & 4 & (3.9\%) \\
\hline $\begin{array}{l}\text { Directed learning) is effective to motivate the students } \\
\text { for learning } \\
\text { The Compensatory Academic Mechanism (Self }\end{array}$ & 4 & $(3.9 \%)$ & 18 & $(17.5 \%)$ & 23 & $(22.3 \%)$ & 22 & $(21.4 \%)$ & 3 & $(2.9 \%)$ \\
\hline $\begin{array}{l}\text { Directed learning) was implemented -- to your } \\
\text { satisfaction. }\end{array}$ & 4 & (3.9\%) & 14 & (13.6\%) & 23 & (22.3\%) & 26 & (25.2\%) & 3 & $(2.9 \%)$ \\
\hline
\end{tabular}


Table 4: Responses from the feedback IV BDS $(n=65)$

\begin{tabular}{|c|c|c|c|c|c|c|c|c|c|c|}
\hline & & SD & & D & & $\mathrm{N}$ & & A & & SA \\
\hline Dental Health professionals need $100 \%$ learning & - & - & 7 & $(6.7 \%)$ & 5 & $(4.8 \%)$ & 32 & $(30.8 \%)$ & 21 & $(20.2 \%)$ \\
\hline $\begin{array}{l}\text { Compensatory Academic Mechanism (Self Directed } \\
\text { Learning) is very good mechanism for the same }\end{array}$ & 7 & $(6.7 \%)$ & 15 & $(14.4 \%)$ & 23 & $(22.1 \%)$ & 16 & $(15.4 \%)$ & 4 & $(3.8 \%)$ \\
\hline $\begin{array}{l}\text { The Compensatory Academic Mechanism (Self } \\
\text { Directed learning) helps you to get near -- } 100 \% \\
\text { learning of your schedule. }\end{array}$ & 3 & $(2.9 \%)$ & 21 & (20.2\%) & 19 & (18.3\%) & 16 & (15.4\%) & 6 & $(5.8 \%)$ \\
\hline $\begin{array}{l}\text { Your experience during Compensatory Academic } \\
\text { Mechanism (Self Directed learning) is good } \\
\text { The Compensatory Academic Mechanism (Self }\end{array}$ & 3 & $(2.9 \%)$ & 10 & $(9.6 \%)$ & 32 & $(30.8 \%)$ & 19 & $(18.3 \%)$ & 1 & $(1 \%)$ \\
\hline $\begin{array}{l}\text { Directed learning) is effective to motivate the students } \\
\text { for learning } \\
\text { The Compensatory Academic Mechanism (Self }\end{array}$ & 4 & $(3.8 \%)$ & 18 & $(17.3 \%)$ & 9 & $(8.7 \%)$ & 28 & $(26.9 \%)$ & 6 & $(5.8 \%)$ \\
\hline $\begin{array}{l}\text { Directed learning) was implemented -- to your } \\
\text { satisfaction. }\end{array}$ & 3 & $(2.9 \%)$ & 18 & $(17.3 \%)$ & 21 & $(20.2 \%)$ & 20 & $(19.2 \%)$ & 3 & $(2.9 \%)$ \\
\hline
\end{tabular}

But there are incidences when students cannot attend all the lectures, clinics or practical classes due to various reasons. To compensate this, it is essential to develop the self-directed learning mechanisms, which will help students to learn what has been missed out by them.

\section{Self-directed learning in health professional education}

1. SDL is an important component of CLM. In self-directed learning, learners take the initiative in making use of resources rather than simply react to transmissions from resources, thus helping learners to learn more and learn better. Self-directed learning is defined by Marsick and Watkins (2001) as "the process in which individuals take on the responsibility for their own learning process by diagnosing their personal learning needs, setting goals, identifying resources, implementing strategies and evaluating the outcomes. Motivation is the key to a successful selfdirected learning experience. Dental students are motivated by the opportunity to learn new skills, improve their knowledge, and develop attitudes that can improve their work performance. Selfdirected learning has become an essential tool for learning in the modern era.

2. The internal or external motivation is enough for initiating and refection of action thereby acts as an inductive self-directed learning process that helps the learner to be linked to learning of others.
3. A SDL mechanism has its base in adult education. SDL views as an ownership amongst the students in their own learning process. SDL inculcates self-management with self-monitoring process whereby the students monitor, evaluate and regulate their cognitive learning strategies. Traditionally, attendance has been one of the factors that determine the eligibility of students to appear for exams. Most universities in India stipulate $70-80 \%$ attendance to be eligible for appearing in exams with additional $5 \%$ at the discretion of the dean. $20 \%$ absence is contingency benefit for unavoidable circumstances like illness, accidents, etc. Unfortunately, some students regard this as an excuse to miss out on $20 \%$ of the classes even in the absence of genuine reasons. This leads to missed T-L experiences for the students and cumulatively may hamper their learning experience. All the topics in medical sciences are important for comprehensive understanding of the subject and hence the student cannot afford missing these lectures. Additionally, in cases where the student is genuinely unable to attend classes due to unavoidable circumstances, the present system doesn't provide for any coping mechanism to fillip the gap in the students' knowledge.

The present study aimed to address the above problems in a way that would benefit the student by compensating for the missed classes and also make it a voluntary, 
enjoyable experience. The core principle of adult education, self-directed learning, is at the heart of this concept.

SDL is one of the pivotal pillars of the compensatory learning mechanism. CLM has been developed and implemented in order to observe the effectiveness in learning process. CLM involves student participation in compensation of learning the topics whatever has been missed out by them. The teacher's involvement in CLM is to give assignments in the form of write-ups, seminars or a presenting a case / practical in the class or at individual level and to evaluate them on completion.

Teachers are expected to motivate the students for developing an attitude for self-directed learning \& CLM can be implemented to compensate for the permissible absence of $25 \%$ in theory \& $20 \%$ in practical/clinics permitted by the universities. This compensation of learning preferably is to be executed by the same faculty that has originally delivered the lecture or conducted the practical/clinic. This will develop an understanding in students that each \& every topic is equally important \& necessary to learn. This may also help to develop a good rapport between teacher \& students. Ultimately this will improve the performance of the students.

A multitude of factors play a role on the outcome of any university examinations, e.g. the understanding of the subject and the manner in which it is taught, stress levels of candidates, difficulty level of the question paper, protocol of answer paper evaluators. It is very difficult to assess whether the intervention is causally associated with such outcome. It is obvious however, that for adequate understanding of subject, some form of guided learning is essential for the student. When students miss classes, the CLM is aimed to ensure that learning is not hindered.

In this mechanism, students and teachers come together and agree on mode of learning experience like presentation, demonstration of clinical skills or write-up, this encourages the adult student to exercise his discretion and thus develops interest in the exercise. This leads to higher level of commitment and involvement, increase in communication with teachers, leading to more effective learning.

CLM is a pragmatic and dynamic platform which is amenable to any form of learning. For example, students get a chance to improve upon various skills in different domains. Psychomotor skills may be improved by performing a CLM in clinical training; cognitive domain may be improved upon by performing case based discussions, write ups, presentations, problem based learning, etc. A word of caution may be added here that CLM should not be used for assessment; its purpose is to plug the gaps and improve the knowledge of the student across domains. Adults are independent and self-directing. They have accumulated a great deal of experience, which is a rich resource for learning. They value learning that integrates with the demands of their everyday life. They are more interested in immediate, problem- centred approaches than in subject centred ones. They are more motivated to learn by internal drives than by external ones.

\section{Summary \& conclusion}

Absenteeism in professional education is an issue that has not received adequate attention by researchers, academicians and policy makers. Teachers by and large follow university guidelines for managing students with inadequate attendance. On one side of the spectrum are students who are not allowed to appear for exams because they are just short of stipulated attendance, even though they may have had genuine and valid reasons for absence. On the other side are those who have deliberately scraped through the minimum attendance requirement, wilfully missing out sessions, exploiting the loop-hole in university guidelines which emphasizes on quantity (percentage of classes attended) and not on the quality of learning attained. A more rational system needs to be in place to tackle absenteeism wherein students are given a chance to complete \& augment their learning while teachers are provided with an opportunity to deal with this problem by motivating the students through their internal drives rather than by punitive regulations (such as minimum percentage of attendance required). It is the authors' opinion that CLM provides such a prospect. . Students in CLM complete \& augment their learning and teachers ensure that teaching is complete by allotting and supervising CLM assignments. Both of them are partners in the CLM endeavour where they harness each other's motivations and skills to enhance the teaching-learning experience. It would be interesting to study the results of 
newer studies including larger sample size and different courses (dental, medical, paramedical) and compare them with the results of present study. Based on the results of the present study, the authors recommend a change in attendance policy and formalize CLM in curriculum.

\section{References}

Bolhuis S. (1996) Towards Active and Self-directed Learning. Preparing for Lifelong Learning, with Reference to Dutch Secondary Education. Paper presented at the Annual Meeting of the American Educational Research Association (New York, NY, April 8-12, 1996).

Donatelle, R. (2009) Promoting Healthy Behavior Change. Health: The basics, Pearson, p.4.

Garrison, D. R. (1997) Self-directed learning: Toward a comprehensive model, Adult Education Quarterly, 48, 1, pp. 18- 33.
Marsick, V.J. and Watkins,K.E. (2001) Informal and incidental learning, New Directions for Adult and Continuing Education 2001,89, pp .25-34

McKenzie, J.F., Neiger, B.L., Thackeray, R. (2016) Planning,implementing \& evaluating health promotion Programmes:A primer, Pearson, .pp. 34

MUHS/XP-30/006/......../2012, Circular No. 16/2012 dated 27/06/2012 .Available at: http://www.muhs.ac.in/upload/Circular_16_Progra mme_Exam_bds_Unani_Pharma_031012_03102 012_1446.pdf.

Murad, M. H., Varkey,P. and Ann (2013) Viewpoint: Self-directed learning is not an easy way out for the teacher, South Sudan Medical Journal , 6,2 Downloaded from www.southsudanmedicaljournal.com

Rager, K. B. (2003) The self-directed learning of women with breast cancer, Adult Education Quarterly, 53,4, pp.277-293. 